IZA DP No. 6853

Access to Public Schools and the Education of Migrant Children in China

Yuanyuan Chen

Shuaizhang Feng

September 2012 


\title{
Access to Public Schools and the Education of Migrant Children in China
}

\author{
Yuanyuan Chen \\ Shanghai University of Finance and Economics \\ Shuaizhang Feng \\ Shanghai University of Finance and Economics \\ and IZA
}

Discussion Paper No. 6853

September 2012

\author{
IZA \\ P.O. Box 7240 \\ 53072 Bonn \\ Germany \\ Phone: +49-228-3894-0 \\ Fax: +49-228-3894-180 \\ E-mail: iza@iza.org
}

\begin{abstract}
Any opinions expressed here are those of the author(s) and not those of IZA. Research published in this series may include views on policy, but the institute itself takes no institutional policy positions.

The Institute for the Study of Labor (IZA) in Bonn is a local and virtual international research center and a place of communication between science, politics and business. IZA is an independent nonprofit organization supported by Deutsche Post Foundation. The center is associated with the University of Bonn and offers a stimulating research environment through its international network, workshops and conferences, data service, project support, research visits and doctoral program. IZA engages in (i) original and internationally competitive research in all fields of labor economics, (ii) development of policy concepts, and (iii) dissemination of research results and concepts to the interested public.
\end{abstract}

IZA Discussion Papers often represent preliminary work and are circulated to encourage discussion. Citation of such a paper should account for its provisional character. A revised version may be available directly from the author. 
IZA Discussion Paper No. 6853

September 2012

\section{ABSTRACT}

\section{Access to Public Schools and the Education of Migrant Children in China}

A significant proportion of migrant children in China are not able to attend public schools for lack of local household registration (HuKou), and turn to privately-operated migrant schools. This paper examines the consequences of such a partially involuntary school choice, using survey data and standardized test scores from field work conducted in Shanghai. We find that migrant students who are unable to enroll in public schools perform significantly worse than their more fortunate counterparts in both Chinese and Mathematics. We also use parental satisfaction and parental assessment of school quality as alternative measures of the educational outcome and find similar results. Our study suggests that access to public schools is the key factor determining the quality of education that migrant children receive.

JEL Classification: $\quad$ I28, J15, O15

Keywords: education of migrant children, migrant school, standardized test score

Corresponding author:

Shuaizhang Feng

715 Economics Building

111 Wuchuan Road

Shanghai University of Finance and Economics

Shanghai 200433

China

E-mail: shuaizhang.feng@gmail.com

\footnotetext{
* We are grateful to Li Ma and Jianing Zhang for assistance in conducting the field work. We thank participants at the $4^{\text {th }}$ CIER/IZA conference at Bonn for valuable comments. Feng cordially acknowledges financial support from the National Science Foundation of China (Project\# 70803029).
} 


\section{Introduction}

One of the main drivers of China’s phenomenal economic growth during the past three decades has been the large-scale and persistent rural-to-urban migration. As a consequence, a half of China's 1.3 billion people now live in cities, as compared to only twenty percent in the early 1980s. Nevertheless, researchers have expressed concerns over China’s so called “pseudo-urbanization” (see e.g. Henderson, 2009 and Yew, 2012). The majority of rural migrants in cities do not possess a local household registration $(\mathrm{HuKou})$, thus are excluded from full access to pension, health care, public education and other social benefits at the place they live. Based on the 2010 Census, there are about 260 million such "non-HuKou" migrants who work and live in a locality other than where his/her official HuKou is registered at.

Among all non-Hukou migrants, it is estimated that over 20 million are children aged between 6 and 14 . Although all Chinese school-age children are entitled to a free and compulsory 9-year education by law, the Chinese educational system designates elementary education to local governments at the county/district level. Funding for elementary education is allocated by the number of children with $\mathrm{HuKou}$ and not portable across administrative units. Therefore, local authorities lack the incentives and financial resources to accommodate the educational needs of migrant children, despite directives from the central government that urge them to do so. A significant proportion of migrant children is thus excluded from the public education system and has to enter the so called "migrant schools", which started as informal schools by migrants themselves.

The educational dilemma faced by migrant children is a reflection of the discordance between China's swift urbanization process and the historically-rooted, still omnipotent HuKou system (Chan and Buckingham, 2008). We believe it is important to empirically assess the consequences of such a HuKou-based discriminatory educational policy for several reasons. First of all, the sheer number of migrant children makes their education a top national development priority for China. Despite the government's tremendous efforts to upgrade both rural and urban public schools, the HuKou system makes the education of migrant children a 
distinctive challenge as they do not fit into the usual rural-urban dichotomy. If migrant children do not receive appropriate elementary education, it is likely that their lifetime welfare, including labor market outcomes, will be adversely affected. Society in general would also face negative externalities due to increased poverty and a possible rise in crime. In addition, if trends regarding the rural-to-urban migration and the urbanization process continue, the number of migrant children is expected to grow. The rural areas also hold a significant reservoir of potential migrant children, as there are around 60 million so called "left-behind" children. Their parents work in cities but they stay with grandparents or other relatives at home. Were the urban educational system more accommodating, many of them would have chosen to migrate to cities to stay with their parents.

Secondly, any policy discussion regarding the reform of China's educational system should be based on empirical facts rather than just political ideology or public sentiments. One of the key policy issues regarding migrant children's education is the roles public schools and migrant schools should play, respectively. Should the local public schools admit unconditionally all migrant children coming to their doors? Should migrant schools be allowed to continue to exist? ${ }^{1}$ Should the governments even subsidize migrant schools so as to make them better suited to teach migrant children? To answer these questions, one has to first have a correct understanding of the relative qualities of education that migrant children receive in public schools and migrant schools. Furthermore, in order to make exact policy recommendations, it is necessary to quantify the quality differences using measures such as test score gaps, as we do in this paper.

Last but not least, China's situation provides a unique opportunity to study the role of public elementary education for disadvantaged children, such as children of migrants or those with poor family background. Many other developing countries are also undergoing rapid rural-to-urban migration and urbanization process. Although a formal institution such as $\mathrm{HuKou}$ that excludes access to public schools does not exist in other

\footnotetext{
${ }^{1}$ While migrant schools are usually viewed as inferior to public schools. Some scholars have argued that migrant children may receive better education in migrant schools as they would face more discrimination from teachers and classmates in public schools (Zhou, 2006).
} 
countries, the situation could still be similar when the urban educational infrastructures are unable to accommodate the influx of migrant children. In that case, would market-based responses, such as the establishments of migrant schools, be adequate to take care of the needs of migrant students? Or is it necessary for the governments to take a more proactive role? Governments need to understand the tradeoffs involved before taking any preparatory actions.

In this paper, we use self-collected survey data and administered standardized tests to study the educational consequences associated with attending migrant schools. Our study distinguishes itself from the existing literature in a number of ways. To compare academic performances of students in different schools, we gave standardized Chinese and Mathematics tests to all fourth grade students surveyed. We also collected detailed information on students and parents, which allow us to disentangle school effects from student and family background effects. More importantly, we have utilized policy changes in Shanghai to correct for possible selection-bias resulting from migrant children's nonrandom enrollments into public and migrant schools. In addition to test scores, we have used two other more comprehensive albeit subjective measures of school quality: parental overall satisfaction and parental assessed school quality.

The rest of the paper goes like follows. Section 2 provides background information on the education of migrant children in China and briefly reviews existing studies. This is followed by a description of the data source and the empirical methodology in section 3. The main empirical results are reported in section 4 . The last section concludes with some policy implications.

\section{Background and the existing literature}

The educational problem for migrant children is closely related to China's HuKou system, which was first established in the 1950s. A person or household has either "agricultural" or "non-agricultural" HuKou specific to a locality. Under the HuKou system, internal migration was tightly controlled and only 
government-granted migration were possible, which usually involved a change of $\mathrm{HuKou}$ status from the source to the destination locale. Since the 1980s, the HuKou system has evolved and the agricultural/non-agricultural divide has weakened considerably after the abolition of rationed grain in the early 1990s. On the other hand, the geographic dimension of HuKou has strengthened due to the increased regional inequality (Kanbur and Zhang, 2005; Zhang, 2006). Today, HuKou is still one of the most important mechanisms determining entitlements to public welfare and urban services, which are mainly funded by local governments (Chan and Buckingham, 2008). Thus, to some extent, HuKou is an internal "citizenship” for Chinese people.

Because migrant children do not have local HuKou in the place they live, they are not entitled to free compulsory education stipulated by Chinese laws. In Chinese cities, two criteria are important for public schools to admit students. First, students must reside within the local school district in the city; and second, students must be registered in the school district as well, i.e., having local HuKou. The reasoning behind these regulations is that the education budget for elementary schools and middle schools is allocated through local governments at the county/district level. State funding for compulsory schooling differs vastly by locality and is not portable across different cities. If migrant children are allowed to attend local schools, it actually increases the financial burden of the local government (Liang and Chen, 2005).

Migrant schools started in the early 1990s as a market-based response to the educational needs of migrant children. Since its inception, migrant school flourished quickly, and by the early 2000s they played a more important role in admitting migrant children in cities than public schools. For migrant parents, the fees charged by migrant schools are far more affordable than those necessary to enroll their children in a public school. Migrant schools are typically established by migrant entrepreneurs, are for-profit, and offer inferior conditions. Migrant schools are subject to constant closures and changes of places as they do not have a clear legal standing within China's educational system (Han, 2004). In recent years, the conditions in many migrant 
schools have improved substantially, thanks to donations from the society and in some cases subsidies from the local government. Still, migrant schools and their students are "not-in-the-system”. Because a student can only take the college entrance exam in the province where her HuKou is, migrant children face more and more difficulties as they go up the educational ladder. For example, in Shanghai, almost all migrant children can go to a primary school (either a public or a migrant one), but not all of them can go to a local middle school as migrant middle schools are not allowed to operate and there are not enough public middle schools. Beyond middle school, migrant youths have little educational opportunities if they choose to stay in Shanghai, except for some vocational high schools.

Government policies regarding migrant children’s education have evolved along the way, especially in terms of access to public schools. Initially, non-HuKou children were allowed to enroll in public schools only if they are willing to pay a hefty "out-of-district" fee to cover the additional educational cost, on the condition that the schools have extra capacity. Because such additional fees are prohibitive for most rural migrant families, children of migrant farmers are either "left-behind" or have to go to migrant schools, or drop out of school. In response to this reality, the central government has issued a directive in 2003 stating that educating migrant children is the "responsibility" of the local government in the destination areas, and public schools should be the primary channel through which migrant children receive education. Nevertheless, local governments only complied with this directive partially, and to different degrees, as no specific funding was provided for such purposes. Among all major migrant-receiving cities, Shanghai is probably among the most accommodating ones in terms of meeting migrant children's education needs. In 2008, Shanghai government launched a "three-year action plan for the education of migrant children", which is characterized by further opening up public schools to migrant children and subsidizing migrant schools. By 2011, all migrant schools in Shanghai's central districts have been shut down and migrant students in these districts are transferred to public schools. In peripheral districts where not enough public schools exist, authorized migrant schools are 
still allowed to operate, and receive subsidies from the government. ${ }^{2}$ Currently, among around half million migrant students in Shanghai, about 70 percent of them are enrolled in public schools while the rest study in migrant schools.

Despite the importance of the issue, the literature on migrant children's education has been mostly anecdotal or descriptive (see e.g.: Han, 2004, Kwong, 2004, Zhou, 2006, Goodburn, 2009). One notable exception is the study by Lai et al. (2011), which compares test scores of students in migrant schools in Beijing with those in rural public schools in Shaanxi. They find that students in migrant schools perform significantly better than their counterparts in rural public schools in one of the poorest regions of the country. While it is interesting to contrast migrant schools in cities with rural public schools where the migrant children came from, we believe it is more policy-relevant to compare migrant schools with urban public schools, as most migrant children are expected to stay in cities. ${ }^{3}$

\section{Data and Methodology}

\subsection{Description of the Data}

Data for this study were collected from 20 elementary schools in Shanghai in November 2010. All fourth grade students from 11 public schools and 9 migrant schools were interviewed and given standardized tests on Chinese and Mathematics. Because the municipality government has shut down all migrant schools in the central districts of Shanghai, all 9 migrant schools were from the peripheral districts. On the other hand, 5 public schools were from the central districts and the rest were from the peripheral districts. All public schools we selected admitted a significant number of migrant students, with the percentage of non-HuKou students

\footnotetext{
${ }^{2}$ For the academic year of 2011-2012, all migrant schools in Shanghai receive around RMB4,500 per pupil subsidy from the local governments, and in exchange, have waived tuitions for all students.

${ }^{3}$ Lai et al (2011) also compare migrant students in migrant schools with those in public schools in Beijing and find a significant test score gap. Nevertheless, they only surveyed four public schools in Beijing and did not report the empirical results in their paper. Their results are also subject to potential criticism of selectivity bias as they use simple multivariate regressions and do not control for unobserved factors that might be important in affecting children's school choices.
} 
ranging from 27 percent to 83 percent. We therefore excluded those elite schools where competition in terms of enrollment is fierce even for students with Shanghai HuKou.

We chose fourth grade students because there is negative sample selection among the fifth graders. In the fifth year, many well-performed migrant students return to their hometown as they face obstacles in entering middle schools and high schools in Shanghai. On the other hand, younger children are more likely to have difficulties in understanding our questionnaires. To avoid sample selection among the students within schools, we chose to sample all fourth grade students in the schools selected. Thanks to the cooperation from school administrators, our response rate is close to 100\%. Each school has between 2 to 6 classes in the fourth grade. Class size ranges from 18 to 59 students.

We collect information at the school, class and student/parent level through the following: 1) a school survey completed by a school administrator; 2) a class survey completed by the master teacher of the class; 3) a student survey completed by students in class under the instruction of our surveyors; 4) a student information sheet completed by the master teacher; and 5) a parent survey completed by parents. The school survey collects basic information about the school, such as its history, number of classes and students, basic characteristics of all teachers, sources of funding, requirements for enrolling students without Shanghai HuKou, fees, and so on. The class survey asks questions about the whole class, such as its curriculum, educational background and teaching experiences of course instructors. The student survey asks the students questions such as their prior history of school transfer, time use after school, whether parents have helped them with study after school, and their personal feelings about going to school, etc. The student information sheet collects basic information about each student in a class, such as their HuKou status, gender, age, height and weight, disability status, class performance as evaluated by the master teacher. Lastly, the parent survey collects information about parents, including their age, education and income, migration history, expectations on their children's education, parental assessment of school quality, overall satisfaction with the current school, among 
other things. Students were instructed to give the parent survey questionnaire to their parents to complete, and bring back the questionnaires on the next school day. In case some questions were unfilled, our interviewers would work with the master teacher to resolve the issue, and check by telephone with parents directly if necessary. ${ }^{4}$

We give standardized Chinese and Mathematics tests to all students in both public schools and migrant schools. Because migrant schools are considered as only "informal" schools and not part of the local educational system, the educational bureaus do not give standardized tests to students in migrant schools. The school self-administered tests also do not reflect the true performance gap between migrant schools and public schools. Actually, because migrant schools are private schools and face competition in terms of student enrollment, many are reported to give inflated scores to their students. Our Chinese and Mathematics tests are designed by experts outside the schools surveyed, and incorporated different curriculum requirements by Shanghai and other provinces. Testing time for each subject is 20 minutes, with both the master teacher of the class and one of our interviewers proctoring.

\subsection{Empirical methodology}

In our empirical work, we use the following model:

$$
Y_{i}=\beta_{0}+\beta_{1} M_{i}+\beta_{2} X_{i}+\varepsilon_{i}
$$

Where $Y_{i}$ is the education outcome variable that we are interested in. In this paper, we consider three different outcomes, including standardized test scores, parental overall satisfaction, and parental assessment of the school quality. $M_{i}$ is a dummy variable for the type of school, which equals 1 if student $\mathrm{i}$ is enrolled in a migrant school, 0 if in a public school. $X_{i}$ is a vector of control variables including student and parental characteristics, such as age and gender of the student, parental educational and family income. $\varepsilon_{i}$ is the error

\footnotetext{
${ }^{4}$ All questionnaires are available from the corresponding author upon request.
} 
term that includes all other factors that also affect the educational outcome. In our empirical work, we cluster the error term at the class level to capture within-class correlations in $\varepsilon_{i}$.

Because school type is not exogenous and there is selection into public or migrant schools, we adopt an instrumental variables (IV) approach and formally model the school selection process as follows.

$$
M_{i}=\gamma_{0}+\gamma_{1} Z_{i}+\gamma_{2} X_{i}+\vartheta_{i}
$$

where $M_{i}$ is the dummy variables for the school type. $X_{i}$ is the same control vector as in equation (1). $Z_{i}$ is the vector of instruments. Together, equations (2) and (1) constitute the instrumental variables method of our empirical model. In order to estimate $\beta_{1}$ consistently, we need our instruments $Z_{i}$ to affect the school type choice but uncorrected with the error term in (1).

When the test score is used as the outcome variable, the coefficient $\beta_{1}$ corresponds to the test score gain if a migrant student is reassigned to a public school, holding everything else unchanged. It captures the overall test score difference between migrant schools and public schools and reflects effects of various factors both at the school level, such as the quality of school administrators and school infrastructures, and at the class level, such as the qualities of teachers and classmates. This paper does not try to disentangle these effects for the following reasons. First, from the viewpoint of identification, it would be difficult to separate those effects given that the variations between public schools and migrant schools far outweigh the variations within public or migrant schools. In another word, migrant schools are much worse than public schools virtually in all observed dimensions, thus it would be difficult to attributing the overall test score gap to any specific factors. Second, there might be important interacting effects between school type and various factors at the school and class levels. Third, it is well-known in the education literature that many important determinants of education quality are difficult to observe or measure for outside researchers. For example, Rivkin et al. (2005) provide evidence that teacher quality is important in explaining variations in test scores despite that observed teacher characteristics such as education and teaching experience have little explanatory power. 
Table 1 shows some suggestive evidence on the relative quality of teachers in migrant schools as compared to public schools. Teachers in migrant schools are considerately less experienced, with $23 \%$ of them having less than 3 years' experience, while the corresponding percentage in public schools is only $4 \%$. $85 \%$ of teachers in public schools have more than 10 years' experience, while only $28 \%$ of migrant school teachers have similar experience. In terms of education, $58 \%$ of teachers in public schools have at least college education while only $16 \%$ of all teachers in migrant schools do. Teachers of migrant schools also earn much less than their counterparts in public schools, with most of them (81\%) earning less than RMB3,000 per month. In sharp contrast, over 70\% of teachers in public schools earn more than RMB5,000 and virtually no one earns less than RMB3,000. Considering that public school teachers also enjoy much better fringe benefits and job security, the overall gap in terms of compensation is even larger. This at least partially reflects the productivity difference between teachers in migrant and public schools (See e.g. Card and Krueger, 1992).

\section{Empirical Results}

\section{1: Summary Statistics}

Table 2 lists summary statistics on test scores and some key characteristics of students and their families, by three groups separately: students with Shanghai HuKou (Shanghai students) in public schools, students without Shanghai HuKou (migrant students) in public schools, and migrant students in migrant schools. Among the three groups, Shanghai students have the highest test scores on average in both Chinese and Mathematics. Within public schools, Shanghai students on average score 3 points higher than migrant students in both tests. However, these differences are much less pronounced compared to the differences between migrant students in and out of public schools. Average Chinese score for migrant students in public schools is higher than that of migrant students in migrant schools by 10 points. The corresponding test score gap in Mathematics is 16 points, or slightly over one standard deviation in terms of the distribution of Mathematics 
scores for Shanghai students in public schools. ${ }^{5}$ The test scores of students in migrant schools are also more dispersed, as shown in Figure 1.

Table 2 also presents two more subjective measures of educational outcome. All parents were asked about the overall satisfaction level about the school their children attend. Among the three groups, parents of migrant children in public schools are the most satisfied, with $45 \%$ of them reporting "very satisfied". For parents of Shanghai students and parents of migrant children in migrant schools, the percentages of reporting "very satisfied" are only $27 \%$ and $22 \%$, respectively. For parents of migrant children, we have also asked them to directly assess the quality of schools as compared to average-quality schools in their home town. $79 \%$ of migrant parents from public schools report that the current school qualities are better than schools from their hometown, while only $45 \%$ of migrant parents from migrant schools report the same.

In terms of student characteristics, compared to Shanghai students, migrant students are older, more likely to be boys with siblings, and less likely to have attended kindergarten. This is especially so for migrant students from migrant schools. Parents of migrant students from migrant schools have significant lower levels of education and lower family incomes than migrant parents from public schools. Shanghai parents have much higher education levels than migrant parents, but their family incomes do not differ much from migrant parents from public schools. It is important to note that the public schools we have selected are in the lower end of the distribution in terms of school quality among all public schools in Shanghai. Parents of Shanghai students from these public schools are thus of relatively lower social economic statuses as compared to other Shanghai parents who could transfer their students to better schools.

Lastly, migrant students in migrant schools and public schools differ significantly in terms of the composition of province of origin. Students from Jiangsu, which is a developed province adjacent to Shanghai, are more likely to enter public schools. The opposite is true for students from Anhui, a relatively undeveloped

\footnotetext{
${ }^{5}$ Throughout the paper we will use the test score distribution of Shanghai students in public schools as the benchmark when talking about standard deviations.
} 
province and a major migrant-sending region. Similarly, students from Sichuan are also more likely to be in migrant schools.

Overall, comparisons between migrant children in public schools and migrant schools in terms of student and family characteristics suggest there might exist substantial nonrandom selection into different types of schools. Therefore, one cannot simply compare educational outcomes of migrant students from the two types of schools. Instead, it is necessary to first understand the process through which migrant parents choose different types of schools, which we do in the next subsection.

\section{2: The school choices of migrant children}

Table 3 displays regression results for migrant students in public and migrant schools in terms of their school type choices, as stated in Equation (2). Student characteristics included on the right-hand side are HuKou status (rural or urban), sex, age, and whether he/she is a single child, whether he/she has attended kindergarten, daily time spent on homework. Parental characteristics included are number of years since parents first migrated, parental education levels, family income, father's occupation and province of origin. Not surprisingly, if a student has urban $\mathrm{HuKou}$, is the only child in his/her family, and has attended kindergarten, then he/she is more likely to enter public schools. Family income levels and mother's education level are also positively associated with the probability of enrolling in public schools.

In addition, we have also included two variables on whether parents lived in a central or peripheral district of Shanghai in 2008 as instrument variables in the regression, with the omitted group being those who were not in Shanghai in 2008. Compared to those who were not in Shanghai in 2008, migrant students whose parents lived in a central district are 56\% more likely to attend a public school, while those whose parents lived in a peripheral district are $11 \%$ more likely to enter a migrant school.

We chose parents' living place in 2008 as the instrument because Shanghai government officially 
launched the "three-year action plan for the education of migrant children" at the end of 2008, which resulted in a complete shut-down of migrant schools in all central districts by 2011. Therefore, if a migrant child lived in a central district of Shanghai in 2008, then the probability of enrolling in a public school would be much higher than if he/she lived in a peripheral district in 2008. Under the assumption that migrant parents did not know about the policy change before it went into effect or that they did not respond to the policy change and choose to live in a central district for the sake of children's education, this provides a natural experiment on migrant students' school choices. In another word, our identification strategy utilizes the geographic variation (central vs. peripheral districts) in school types that are caused by exogenous policy changes.

More generally, our IV method would not work if parents' living arrangements are correlated with the error term in equation (1). For example, if parents who care more about children's education are also more likely to live in a central district for whatever reason, then the IV estimates would also be upward-biased. We take this possibility seriously and investigate in detail what factors determine whether parents lived in a central district, restricting the sample to those who were in Shanghai in 2008. The results are reported in Table 4. We find that the two most important predictors of whether migrants live in a central or peripheral district are 1) father's occupation, and 2) province of origin. Those working in the manufacturing sector are more likely to live in peripheral districts as factories are located away from the city center, while those working in the service sectors are more likely to live in a central district. Migrants from Anhui or Sichuan are also more likely to live in peripheral districts. This finding is consistent with our numerous personal conversations with migrants in Shanghai that suggest migrants' living location choices are primarily driven by where they could find employment opportunities. The existing literatures also suggest that migrant workers use township networks extensively in locating a job and a living place (Zhao, 1999 and Chen, 2010).

For the purpose of identification, Table 4 shows that whether parents lived in a central or peripheral district is conditionally "as if" random. Once we control for father's occupation and province of origin, we 
don't find parents who lived in a central or peripheral district differ in terms of parental education, parental expectation on children's eventual educational attainment, family income, and whether parents think study is important for children's future or not. Therefore, it is reasonable to assume that conditional on father's occupation and province of origin, living places in 2008 are orthogonal to the error term in equation (1) which consists of other unobserved factors that also affect students' test scores.

4.3 The test score gaps between migrants in public and migrant schools

We then estimate equation (1) to evaluate how migrant students' academic performances differ in the two school types. After controlling for gender, age, single child, rural HuKou, kindergarten, time spent on homework, years since parents first migrated, parental education and family income, as well as provinces of origin, we find that the standard test scores of students in migrant schools are significantly lower than migrant students in public schools. As Table 5 shows, based on the OLS regression results, test score gaps between migrant and public schools are 7.6 points in Chinese and 12.1 points in Mathematics. Using instrument variables approach to adjust for possible bias resulted from nonrandom selections into different types of schools (Wooldridge, 2002), we find slightly lower but still highly significant differences in test scores attributing to different school types. In terms of Chinese, a migrant student in a migrant school would score 5.4 points, or 0.4 standard deviation, lower than an identical student in a public school. ${ }^{6}$ The corresponding score gap in Mathematics is 8 points, or over half of a standard deviation. We can safely reject the weak IV hypothesis based on a Wald F-statistics of 67.45. On the other hand, based on the Hansen’s J-statistic, we are not able to reject the (joint) exogeneity assumption for the instrumental variables.

The coefficients on other variables are similar using both OLS and IV. We first examine the effect of various student characteristics. Migrant students coming from rural areas perform worse than those from cities

\footnotetext{
${ }^{6}$ We use the score distributions of Shanghai students in public schools as benchmarks when we talk about standard deviations throughout this paper.
} 
or small towns. Girls on average do significantly better in Chinese than boys, but worse in Mathematics. Compared to those with siblings, Single-child students score around 2 points higher in both subjects. Compared to those who spend less than one hour on homework per day, students who spend between one and two hours post significantly higher scores. However, those who spend over two hours on average have scores less than those spend between one and two hours. Some of the students who spend too much time on homework might have difficulties with the course material. The effect of age on test scores is nonlinear. For those who were born before September 2000 (Aged at least 10 when they started the fourth grade, as compared to the normal age of 9), each additional month of age represents a 0.33 points loss in Mathematics. These students may have repeated a grade due to interruptions in schooling and weak academic performance.

Family background also affects student test scores. Students whose parents migrated earlier perform better on average. One more year's migration experience for parents translates into 0.37 points in Mathematics score and 0.17 points in Chinese score for the student. One possible explanation is that parents who have stayed longer in cities have adapted to local environments better, thus could provide better conditions for their children. Similarly, students from families with at least RMB5,000 monthly income perform better in both Chinese and Mathematics than those from poorer families. Students whose mothers have at least a high school education enjoy a 3.5 point premium in Mathematics while father’s education is not significant.

Our results suggest that school type is one of the most important determinants of the test score gap between migrant students in migrant schools and public schools. It also accounts for a significant share of the overall gap between migrant students and Shanghai students. Taking at face value, if all migrant students in migrant schools are reassigned to public schools, then the overall test score gap between migrant students and shanghai students would shrink from 9.7 to 6 for Chinese (a 3.7 point decrease), and from 13.6 to 8.3 for Mathematics (a 5.3 point decline). On the other hand, if we give all migrant students the same family background (family monthly income, father's education, and mother's education) as Shanghai students, test 
score gaps for Chinese and Mathematics would shrink by only 1.3 points and 4.8 points, respectively.

\subsection{Robustness Checks}

We then perform a series of robustness checks. First, we have used HuKou status to identify migrant students as opposed to Shanghai students. All children without Shanghai $\mathrm{HuKou}$ are classified as migrant students, including those from other cities and from well-off families. This conceptualization is slightly different from the popular view of "migrant children" who usually come from poor uneducated farm households. Since most of those non-HuKou students with good social economic statuses attend public schools, including those students in our sample might cause overestimation of the score gap attributing to schools. In Panel A of Table 6, we restrict the sample to those with rural $\mathrm{HuKou}$, thus exclude anyone that comes from a different city than Shanghai. Panel B excludes all students whose parents have at least college education. Panel C excludes migrant students whose parents earn at least RMB10,000 per month. In all three cases, the coefficients on the migrant school dummy are similar in magnitude to our baseline results (Table 5) for both Chinese and Mathematics.

Some students have transferred schools multiple times as their parents change jobs and living places. These students are more likely to attend migrant schools. Thus, failing to adjust for the effect of school transfers and interruptions in study may result in overestimating the test score gap between migrant schools and public schools. On the other hand, some students may have just transferred to a public school, thus their academic performances reflect more about their prior schooling histories than the qualities of education of their current schools. This may cause the test score gap to be underestimated. In panel D of Table 6, we only include rural students who have never transferred, i.e, they either have stayed in a public school or in a migrant school since they started schooling. Based on the IV specification, the test score gap in Chinese is 6.4, which is slightly larger than in the baseline case, while the gap in Mathematics is 5.8, which is smaller than our baseline 
estimate. Nevertheless, both test score gaps remain quite large in magnitude and statistically significant despite a sharp drop in sample size.

Although we have included a large set of explanatory variables to control for student and family characteristics in the regressions shown in Table 5, it is still possible that some omitted confounding factors might contaminate the estimated coefficient. Therefore, in panel E of Table 6, we include several additional control variables: children’s Body Mass Index (BMI), whether they have ever transferred, whether they just transferred in this semester, whether parents have moved for the purpose of children's education, and whether parents often tutoring children's homework. The estimated score gaps are relatively robust to the inclusion of additional controls, with the Chinese score gap at 5 points and the Mathematics score gap at 8.4.

We also perform extensive robustness checks on our instrumental variables approach used in the analyses. In panel F of Table 6, we use the interaction terms of father's occupation and whether parents lived in central or peripheral districts in 2008 as the excluded variables. Because we have controlled for father's occupation in the test score equation, in doing so, the effects of migrant school on test scores are identified by variations in school types across different living locations within each occupation. ${ }^{7}$ Similarly, panel G uses interaction terms of province of origin with living locations as IV, and panel $\mathrm{H}$ includes both interactions terms used in panels F and G. Finally, panel I further restricts the sample to those who lived in Shanghai in 2008 which led to a $20 \%$ decline in sample size. In all cases, the results are quite similar to our baseline estimates, suggesting that our IV methods are quite robust.

4.5 Beyond test scores: Results on parental overall satisfaction and parental-assessed school quality

So far, we have only used standardized test scores as the outcome variable to measure school quality. But test scores only (roughly) measure what students have learned in certain subjects, and do not capture various

\footnotetext{
${ }^{7}$ See Angrist and Krueger (1991) for a similar approach in using interaction terms as IV and their interpretations.
} 
important aspects of education that people may also care, such as children's physical and mental health, social behaviors, happiness, etc. In this section, we use two alternative measures of outcome: overall parental satisfaction and parental-assessment of school quality as compared to schools from their hometown. In our survey, parents report whether they are "very satisfied", "satisfied”, or "not satisfied” with the current school their children attend. For migrant parents, they also report whether they think the quality of current school is "better than", "similar to", or "worse than" schools from their hometown. Summary statistics for these two variables are shown in Table 2 and discussed previously in section 4.1.

Table 7 show results for both ordered Probit regressions and the IV versions of ordered Probit using seemingly unrelated regression techniques. The numbers shown in the table are marginal effects representing the probability of changing from "satisfied" to "very satisfied" for the first two columns, and the probability of changing from "similar to schools at home" to "better than schools at home" in the last two columns. The corresponding standard errors, all clustered at the class level, are reported in the parentheses.

In general, parents in migrant schools are significantly less satisfied with schools than their counterparts in public schools. Based on the IV ordered Probit results, holding everything else constant, if a student is transferred from a migrant school to a public school, then the probability of reporting "very satisfied" (as compared to "satisfied") would increase by $19 \%$. Because we have controlled for test scores in the regression, this increase in parental satisfaction reflect other dimensions of school quality not captured by test scores. The first two columns of Table 7 also show that parents are more likely to be "very satisfied" if their children score higher in Mathematics. On the other hand, parents of single children, parents who migrated earlier, and fathers with at least high school education are less likely to be "very satisfied", probably due to their higher expectations on schools.

The last two columns of Table 7 report results for parental-assessed school quality. Again, parents from migrant schools are less likely to view their current schools as "better than" schools from their hometown. 
Ceteris paribus, the probability of reporting "better than schools from hometown" is $27 \%$ lower for parents from migrant schools compared to those from public schools. Again, it is important to note that we have controlled for test scores, which do not seem to affect parental assessment of quality as shown in the table. Factors such as whether the child is the only child in his family, whether parents have high school education, and years since parents migrated are not significant, which suggest that parental assessment of quality is a more objective measure than parental satisfaction, consistent with our belief a priori.

Table 7 also reveals some interesting heterogeneities across different source provinces. Parents from Jiangsu are less likely to rate the school quality as "better than schools at home”, which is consistent with the fact that the quality of education in Jiangsu is among the best of all provinces. Sichuan parents are more likely to be satisfied with children's schools than people from other provinces, probably due to their well-known relaxed and casual lifestyle.

\section{Conclusions}

This paper studies the education of migrant children in China, which are estimated to be over 20 million and are still expected to increase in number due to China's continuing urbanization process. Because of the current HuKou system, many of them are not able to enroll in public schools and have to go to privately owned and operated migrant schools. We examine its consequences using survey data and standardized test scores collected in Shanghai. In doing so, we carefully control for other confounders such as student's academic history and family background, and correct for possible self-selection biases using IV approach. We find that school type is the most important determinant of Chinese and Mathematics test scores, as well as parental satisfaction and parental assessed school quality. The effect of school type on test scores is large, and overwhelms many important student and family effects - if all migrant students in migrant schools are reassigned to public schools, then the overall test score gap between migrant students and shanghai students 
would shrink from 9.7 to 6 for Chinese, and from 13.6 to 8.3 for Mathematics.

Our study adds to the broad international literature that shows school quality matters for students' outcome, see e.g. Card and Krueger (1992), Rouse (1998) and Angrist, Bettinger and Kremer (2006). In terms of public policy, our results suggest that either public schools should be made more accessible to migrant children or migrant schools should be improved significantly so that they could better match qualities of public schools. 


\section{References:}

Angrist, Joshua D., Eric Bettinger, and Michael Kremer (2006), "Long-term educational consequences of secondary school vouchers: evidence from administrative records in Colombia” American Economic Review 96(3), 847-862.

Angrist, Joshua D. and Alan B. Krueger (1991), "Does compulsory school attendance affect schooling and earnings?” Quarterly Journal of Economics 106(4), 979-1014.

Card, David and Alan B. Krueger (1992), "Does school quality matter? Returns to education and the characteristics of public schools in the United States” Journal of Political Economy 100(1), 1-40.

Chan, Kam Wing and Will Buckingham (2008), “Is China Abolishing the Hukou System?” The China Quarterly 195, 582-606.

Chen, Yuyu, Ginger Zhe Jin, and Yang Yue, "Peer Migration in China”, NBER Working Paper No. 15671. January 2010.

Goodburn, Charlotte (2009), "Learning from migrant education: A case study of the schooling of rural migrant children in Beijing,” International Journal of Educational Development 29,495-504.

Han, J. (2004). Survey report on the state of compulsory education among migrant children in Beijing. Chinese Education and Society, 37(5): 29-55.

Henderson, J. Vernon (2009), “Urbanization in China: Policy Issues and Options”, Report for China Economic Research and Advisory Programme, Nov 14, 2009.

Kanbur, Ravi; Xiaobo Zhang (2005), "Fifty Years of Regional Inequality in China: A Journey Through Central Planning, Reform and Openness,” Review of Development Economics, 9(1): 87-106.

Kwong, J., (2004). “Educating migrant children: negotiations between the state and civil society.” The China Quarterly 180, 1073-1088.

Liang, Zai, Yiu Por Chen (2007), “The educational consequences of migration for children in China”, Social Science Research, Volume 36, Issue 1, Pages 28-47.

Lai, Fang; Chengfang Liu; Renfu Luo; Linxiu Zhang; Xiaochen Ma; Yujie Bai; Brian Sharbono and Scott Rozelle (2011), "Private Migrant Schools or Rural/Urban public schools: Where should China educates its migrant children?”Rural Education action project, Stanford University, working paper \#224.

Rivkin, Steven G., Eric A. Hanushek, John F. Kain (2005), “Teachers, Schools, and Academic Achievement”, Econometrica 73(2), 417-458.

Rouse, Cecilia E. (1998), "Private school vouchers and student achievement: an evaluation of the Milwaukee parental choice program” Quarterly Journal of Economics 113(2), 553-602. 
Wooldridge, Jeffrey M. (2002). Econometric Analysis of Cross Section and Panel Data. MIT Press, Cambridge, 2002.

Yan, Fei (2005), “Education Problems with Urban Migratory Children in China”, Journal of sociology and social welfare 32(3), 3 - 10.

Yew, Chiew Ping (2012), "Pseudo-Urbanization? Competitive government behavior and urban sprawl in China”, Journal of Contemporary China 21(74), 281-298.

Zhao, Yaohui, (1999), "Leaving the Countryside: Rural-To-Urban Migration Decisions in China”, The American Economic Review, Vol. 89, No. 2, Papers and Proceedings of the One Hundred Eleventh Annual Meeting of the American Economic Association, pp. 281-286.

Zhang, Xiaobo (2006), "Fiscal centralization and political centralization in China: Implications for growth and inequality”, Journal of Comparative Economics 34, 713-726.

Zhou, Hao (2006), “Discussion of the psychological status of migrant children”, Population and Economy, January 2006, 48-54. (In Chinese) 
Table 1 Characteristics of Teachers

\begin{tabular}{lll}
\hline & public schools & migrant schools \\
\hline Teaching Experience (years) & & \\
- Less than 3 years & $4 \%$ & $23 \%$ \\
- 3 to 10 years & $11 \%$ & $49 \%$ \\
- More than 10 years & $85 \%$ & $28 \%$ \\
Teachers' Education & & \\
- High school and below & $6 \%$ & $25 \%$ \\
- Associate degree & $36 \%$ & $59 \%$ \\
- Bachelor's degree and above & $58 \%$ & $16 \%$ \\
Monthly salary & & \\
- Below RMB3000 & $1 \%$ & $81 \%$ \\
- RMB3000 to RMB5000 & $28 \%$ & $19 \%$ \\
- Above RMB5000 & $71 \%$ & $0 \%$ \\
\# of schools & 11 & 9 \\
\hline
\end{tabular}




\begin{tabular}{|c|c|c|c|}
\hline & \multicolumn{2}{|c|}{ Public schools } & \multirow[b]{2}{*}{$\begin{array}{l}\text { Migrant } \\
\text { schools }\end{array}$} \\
\hline & $\begin{array}{r}\text { Shanghai } \\
\text { students }\end{array}$ & $\begin{array}{l}\text { Migrant } \\
\text { students }\end{array}$ & \\
\hline \multicolumn{4}{|l|}{ Standardized test scores } \\
\hline \multirow[t]{2}{*}{ Chinese } & 69.1 & 66.4 & 55.8 \\
\hline & $(12.6)$ & $(13.0)$ & $(14.9)$ \\
\hline \multirow[t]{2}{*}{ Mathematics } & 65.3 & 62.3 & 46.3 \\
\hline & $(15.1)$ & $(16.5)$ & $(20.5)$ \\
\hline \multicolumn{4}{|l|}{ Parental overall satisfaction } \\
\hline not satisfied & 0.06 & 0.02 & 0.1 \\
\hline Satisfied & 0.68 & 0.53 & 0.68 \\
\hline very satisfied & 0.27 & 0.45 & 0.22 \\
\hline \multicolumn{4}{|l|}{ Parental assessment of school quality } \\
\hline worse than schools at home & & 0.05 & 0.13 \\
\hline similar to schools at home & & 0.16 & 0.42 \\
\hline better than schools at home & & 0.79 & 0.45 \\
\hline \multirow[t]{2}{*}{ Age } & 9.4 & 9.59 & 9.64 \\
\hline & $(0.5)$ & $(0.7)$ & $(0.9)$ \\
\hline Female & 0.5 & 0.44 & 0.4 \\
\hline Rural Hukou & & 0.7 & 0.92 \\
\hline Single child & 0.88 & 0.44 & 0.29 \\
\hline Kindergarten & 1 & 0.97 & 0.87 \\
\hline Father is high school graduate or above & 0.78 & 0.42 & 0.25 \\
\hline Mother is high school graduate or above & 0.75 & 0.3 & 0.15 \\
\hline \multicolumn{4}{|l|}{ Monthly family Income } \\
\hline Below RMB3000 & 0.26 & 0.32 & 0.53 \\
\hline RMB3000-5000 & 0.35 & 0.36 & 0.35 \\
\hline Above RMB5000 & 0.39 & 0.33 & 0.12 \\
\hline \multicolumn{4}{|l|}{ Province of origin } \\
\hline Jiangsu & & 0.15 & 0.06 \\
\hline Anhui & & 0.29 & 0.49 \\
\hline Jiangxi & & 0.09 & 0.06 \\
\hline Henan & & 0.08 & 0.10 \\
\hline Sichuan & & 0.07 & 0.11 \\
\hline Other & & 0.34 & 0.20 \\
\hline Number of Students & 498 & 551 & 1,082 \\
\hline
\end{tabular}

Note: numbers in parentheses are standard deviations. 
Table 3 Regression results for whether a migrant student is enrolled in a migrant school

\begin{tabular}{|c|c|c|}
\hline Variables & Coefficients & Standard Errors \\
\hline Rural HuКou & $0.24 * *$ & $(0.11)$ \\
\hline Female & -0.02 & $(0.02)$ \\
\hline Single child & $-0.07 * * *$ & $(0.02)$ \\
\hline Kindergarten & $-0.12 * * *$ & $(0.03)$ \\
\hline \multicolumn{3}{|l|}{ Student age in months } \\
\hline Born after 2001/09 & $-0.02 * * *$ & $(0.00)$ \\
\hline Born between 2000/09-2001/09 & 0.00 & $(0.00)$ \\
\hline Born before 2000/09 & $0.00 *$ & $(0.00)$ \\
\hline 1-2 hour daily homework time & -0.03 & $(0.03)$ \\
\hline$>2$ hours daily homework time & -0.01 & $(0.03)$ \\
\hline Years since parents first migrated & $-0.00 * *$ & $(0.00)$ \\
\hline Family monthly income RMB3000-5000 & $-0.06^{* * *}$ & $(0.02)$ \\
\hline Family monthly income >RMB5000 & $-0.16^{* * *}$ & $(0.04)$ \\
\hline Father has high school education or above & -0.01 & $(0.02)$ \\
\hline Mother has high school education or above & $-0.07 * *$ & $(0.03)$ \\
\hline Living in a central district in 2008 & $-0.56 * * *$ & $(0.06)$ \\
\hline Living in a peripheral district in 2008 & $0.11^{* * *}$ & $(0.04)$ \\
\hline Number of Observations & 1,633 & \\
\hline Province of origin dummies & YES & \\
\hline Father's occupation dummies & YES & \\
\hline Adjusted R-squared & 0.442 & \\
\hline
\end{tabular}

Note: Numbers reported in parentheses are standard errors clustered at the class level. ${ }^{* *},{ }^{* *}$, and ${ }^{*}$ stands for statistical significance at the $1 \%, 5 \%$ and $10 \%$ level, respectively. Students in the omitted group are males with urban $\mathrm{HuKou,} \mathrm{no} \mathrm{experience} \mathrm{in} \mathrm{Kindergarten,} \mathrm{daily} \mathrm{homework} \mathrm{time} \mathrm{less} \mathrm{than} \mathrm{one} \mathrm{hour,} \mathrm{have} \mathrm{siblings,} \mathrm{with}$ family monthly income less than RMB3000, with their parents came to Shanghai after 2008. 
Table 4 Probit results for whether a migrant student lived in a central district in 2008

\begin{tabular}{lcc}
\hline Variables & Coefficients & Standard Errors \\
\hline Father is high school graduate or higher & 0.05 & $(0.12)$ \\
Mother is high school graduate or higher & 0.06 & $(0.13)$ \\
Parent's expectation of children's education attainment & & \\
High school graduate & -0.10 & $(0.43)$ \\
Professional Schools & 0.33 & $(0.42)$ \\
College graduate & 0.32 & $(0.41)$ \\
Family monthly income 3000-5000RMB & 0.16 & $(0.11)$ \\
Family monthly income more than 5000RMB & 0.19 & $(0.13)$ \\
Parents think study is important for children & 0.12 & $(0.09)$ \\
Father's occupation & & \\
Construction & -0.18 & $(0.19)$ \\
Manufacture & $-0.76^{* * *}$ & $(0.19)$ \\
Dinning & $0.56^{* * *}$ & $(0.21)$ \\
Housekeeping & $0.64^{* *}$ & $(0.25)$ \\
Other service(shop, barber or security) & $0.44^{* *}$ & $(0.19)$ \\
Small business & $0.46^{* * *}$ & $(0.13)$ \\
Provinces of origin & & \\
Jiangsu & 0.09 & $(0.16)$ \\
Anhui & $-0.60^{* * *}$ & $(0.11)$ \\
Jiangxi & -0.04 & $(0.17)$ \\
Henan & -0.29 & $(0.18)$ \\
Sichuan & $-0.51^{* * *}$ & $(0.19)$ \\
Constant & & $(0.42)$ \\
Observations & $-1.34^{* * *}$ & \\
\hline
\end{tabular}

Note: Sample in this table only include students whose parents came to Shanghai before 2008. $* * *, * *$, and $*$ stands for statistical significance at the $1 \%, 5 \%$ and $10 \%$ level, respectively. 
Table 5 Regression results on the standardized test scores of migrant students

\begin{tabular}{|c|c|c|c|c|}
\hline \multirow[b]{2}{*}{ VARIABLES } & \multicolumn{2}{|c|}{ Chinese } & \multicolumn{2}{|c|}{ Mathematics } \\
\hline & OLS & IV & OLS & IV \\
\hline \multirow[t]{2}{*}{ Migrant School } & $-7.63 * * *$ & $-5.37 * *$ & $-12.11^{* * *}$ & $-7.99 * *$ \\
\hline & $(1.46)$ & $(2.30)$ & $(2.45)$ & (3.89) \\
\hline \multirow[t]{2}{*}{ Rural Hukou } & $-3.07 * *$ & $-3.58 * *$ & $-4.24 *$ & $-5.69 * *$ \\
\hline & $(1.32)$ & $(1.41)$ & $(2.44)$ & $(2.37)$ \\
\hline \multirow[t]{2}{*}{ Female } & $1.73^{* *}$ & $1.85^{* *}$ & $-1.69 *$ & $-1.54^{*}$ \\
\hline & $(0.85)$ & $(0.82)$ & $(0.92)$ & $(0.93)$ \\
\hline \multicolumn{5}{|l|}{ Student age in months } \\
\hline \multirow[t]{2}{*}{ Born after 2001/09 } & 0.01 & 0.06 & 0.03 & 0.10 \\
\hline & $(0.19)$ & $(0.19)$ & $(0.18)$ & $(0.18)$ \\
\hline \multirow[t]{2}{*}{ Born between 2000/09-2001/09 } & -0.14 & -0.14 & 0.02 & 0.01 \\
\hline & $(0.09)$ & $(0.09)$ & $(0.13)$ & $(0.12)$ \\
\hline \multirow[t]{2}{*}{ Born before 2000/09 } & -0.11 & $-0.13^{*}$ & $-0.31 * * *$ & $-0.33 * * *$ \\
\hline & $(0.08)$ & $(0.07)$ & $(0.10)$ & $(0.10)$ \\
\hline \multirow[t]{2}{*}{ Single Child } & $1.87 * *$ & $2.07^{* *}$ & 1.80 & $2.24 *$ \\
\hline & $(0.81)$ & $(0.81)$ & $(1.20)$ & $(1.24)$ \\
\hline \multirow[t]{2}{*}{ Kindergarten } & -0.43 & -0.11 & 1.90 & 2.43 \\
\hline & $(1.48)$ & $(1.53)$ & $(1.85)$ & $(1.93)$ \\
\hline \multirow[t]{2}{*}{ 1-2 hour daily homework time } & $2.58^{* * *}$ & $2.69 * * *$ & $5.14^{* * *}$ & $5.48^{* * *}$ \\
\hline & $(0.91)$ & $(0.90)$ & $(1.22)$ & $(1.21)$ \\
\hline \multirow[t]{2}{*}{$>2$ hours daily homework time } & 1.57 & 1.60 & $3.31^{* *}$ & $3.51^{* * *}$ \\
\hline & $(1.26)$ & $(1.24)$ & $(1.29)$ & $(1.27)$ \\
\hline \multirow[t]{2}{*}{ Years since migration } & $0.15^{* *}$ & $0.17^{* *}$ & $0.33 * * *$ & $0.37 * * *$ \\
\hline & $(0.07)$ & $(0.07)$ & $(0.10)$ & $(0.11)$ \\
\hline \multirow[t]{2}{*}{ Family monthly income 3000-5000RMB } & 0.85 & 0.97 & 1.12 & 1.31 \\
\hline & $(0.83)$ & $(0.81)$ & $(1.12)$ & $(1.13)$ \\
\hline \multirow[t]{2}{*}{ Family monthly income more than 5000RMB } & $3.82 * * *$ & $4.11^{* * *}$ & $3.37 * * *$ & $4.06 * * *$ \\
\hline & $(1.16)$ & $(1.14)$ & $(1.17)$ & $(1.28)$ \\
\hline \multirow[t]{2}{*}{ Father has high school education or above } & 1.55 & 1.63 & 1.46 & 1.07 \\
\hline & $(1.13)$ & $(1.12)$ & $(1.34)$ & $(1.24)$ \\
\hline \multirow[t]{2}{*}{ Mother has high school education or above } & 0.98 & 1.16 & $2.68 *$ & $3.51^{* *}$ \\
\hline & $(1.05)$ & $(1.04)$ & $(1.51)$ & $(1.48)$ \\
\hline Province of Origin dummies & Yes & Yes & Yes & Yes \\
\hline Father’s Occupation dummies & Yes & Yes & Yes & Yes \\
\hline Observations & 1,633 & 1,633 & 1,633 & 1,633 \\
\hline Adjusted R-squared & 0.150 & 0.146 & 0.181 & 0.174 \\
\hline Wald F statistics for weak IV & & 67.45 & & 67.45 \\
\hline Hansen J-statistic & & 0.080 & & 0.973 \\
\hline P-value J-statistic & & 0.777 & & 0.324 \\
\hline
\end{tabular}

Note: Numbers reported in parentheses are standard errors clustered at the class level. ***, **, and * stands for statistical significance at the $1 \%, 5 \%$ and $10 \%$ level, respectively. 


\begin{tabular}{|c|c|c|c|c|c|}
\hline \multicolumn{2}{|c|}{ Chinese } & \multicolumn{2}{|c|}{ Mathematics } & \multirow{2}{*}{$\begin{array}{c}\text { Sample } \\
\text { size } \\
\end{array}$} & \multirow{2}{*}{$\begin{array}{c}\text { Percentage } \\
\text { of students } \\
\text { in migrant } \\
\text { school }\end{array}$} \\
\hline OLS & IV & OLS & IV & & \\
\hline \multicolumn{6}{|c|}{ Panel A. Only include students with rural $\mathrm{HuKou}$} \\
\hline$-7.56 * * *$ & $-6.29 * * *$ & $-13.21 * * *$ & $-7.97 * *$ & & \\
\hline$(1.68)$ & $(2.37)$ & $(1.21)$ & $(4.03)$ & 1,375 & $71.9 \%$ \\
\hline \multicolumn{6}{|c|}{ Panel B. Only include students with parental education lower than college } \\
\hline$-7.69 * * *$ & $-5.76^{* *}$ & $-11.96^{* * *}$ & $-7.96^{* *}$ & & \\
\hline$(1.46)$ & $(2.35)$ & $(2.49)$ & $(3.95)$ & 1,532 & $67.7 \%$ \\
\hline \multicolumn{6}{|c|}{ Panel C. Only include students with family monthly income less than RMB10,000 } \\
\hline$-7.50 * * *$ & $-5.44 * *$ & $-12.11^{* * *}$ & $-7.86 * *$ & & \\
\hline$(1.43)$ & $(2.27)$ & $(1.15)$ & $(3.67)$ & 1,563 & $67.7 \%$ \\
\hline \multicolumn{6}{|c|}{ Panel D. Only include students with rural HuKou and never transferred } \\
\hline$-7.39 * * *$ & $-6.41 * * *$ & $-10.77^{* * *}$ & $-5.82 * *$ & & \\
\hline$(1.81)$ & $(2.43)$ & $(2.28)$ & $(2.86)$ & 704 & $64.1 \%$ \\
\hline \multicolumn{6}{|c|}{ Panel E. Add more control variables } \\
\hline$-7.01 * * *$ & $-5.04 * *$ & $-11.32^{* * *}$ & $-8.41^{* *}$ & & \\
\hline$(1.45)$ & $(2.35)$ & $(2.31)$ & $(3.84)$ & 1,593 & $65.9 \%$ \\
\hline \multicolumn{6}{|c|}{ Panel F. Add father's occupation \& district interaction terms as IV } \\
\hline$-7.63^{* * *}$ & $-5.03 * * *$ & $-12.11^{* * *}$ & $-8.94 * * *$ & & \\
\hline$(1.46)$ & $(1.58)$ & $(2.45)$ & $(3.41)$ & 1,633 & $66.3 \%$ \\
\hline \multicolumn{6}{|c|}{ Panel G. Add provinces of origin \& district interaction term as IV } \\
\hline$-7.63 * * *$ & $-6.78 * * *$ & $-12.11^{* * *}$ & $-9.27 * * *$ & & \\
\hline$(1.46)$ & $(1.80)$ & $(2.45)$ & $(2.87)$ & 1,633 & $66.3 \%$ \\
\hline \multicolumn{6}{|c|}{ Panel H. Add both father's occupation and provinces of origin to interact with district as IV } \\
\hline$-7.63^{* * *}$ & $-5.94 * * *$ & $-12.11^{* * *}$ & $-7.46 * * *$ & & \\
\hline$(1.46)$ & $(1.23)$ & $(2.45)$ & $(2.28)$ & 1,633 & $66.3 \%$ \\
\hline \multicolumn{6}{|c|}{ Panel I. Exclude those whose parents came to Shanghai after 2008} \\
\hline$-7.88 * * *$ & $-5.66^{* *}$ & $-12.47^{* * *}$ & $-7.72 * *$ & & \\
\hline$(1.53)$ & $(2.21)$ & $(2.48)$ & $(3.91)$ & 1,321 & $65.9 \%$ \\
\hline
\end{tabular}

Note: All regressions use the same control variables as in Table 5 except for Panel E, which also controls for Body Mass Index (BMI), whether the student ever transferred, whether the student just transferred in this semester, whether parent ever changed living place for the sake of children's education, whether parent have helped children's homework. Numbers reported in parentheses are standard errors clustered at the class level. ***, **, and * stands for statistical significance at the $1 \%, 5 \%$ and $10 \%$ level, respectively. 


\begin{tabular}{|c|c|c|c|c|}
\hline & \multicolumn{2}{|c|}{$\begin{array}{l}\text { Parental Overall } \\
\text { Satisfaction }\end{array}$} & \multicolumn{2}{|c|}{$\begin{array}{c}\text { Parental Assessment of } \\
\text { Quality }\end{array}$} \\
\hline & (1) & (2) & (3) & (4) \\
\hline & Oprobit & IV-oprobit & Oprobit & IV-oprobit \\
\hline Migrant School & $\begin{array}{c}-0.25 * * * \\
(0.03)\end{array}$ & $\begin{array}{c}-0.19 * * * \\
(0.05)\end{array}$ & $\begin{array}{c}-0.34 * * * \\
(0.03)\end{array}$ & $\begin{array}{c}-0.27 * * * \\
(0.06)\end{array}$ \\
\hline Chinese /100 & $\begin{array}{l}-0.00 \\
(0.09)\end{array}$ & $\begin{array}{c}0.02 \\
(0.08)\end{array}$ & $\begin{array}{c}0.03 \\
(0.07)\end{array}$ & $\begin{array}{c}0.05 \\
(0.10)\end{array}$ \\
\hline Mathematics / 100 & $\begin{array}{l}0.11^{*} \\
(0.06)\end{array}$ & $\begin{array}{l}0.15^{* *} \\
(0.06)\end{array}$ & $\begin{array}{c}0.06 \\
(0.07)\end{array}$ & $\begin{array}{c}0.11 \\
(0.07)\end{array}$ \\
\hline Rural HuKou & $\begin{array}{c}0.03 \\
(0.04)\end{array}$ & $\begin{array}{c}0.02 \\
(0.03)\end{array}$ & $\begin{array}{c}0.03 \\
(0.03)\end{array}$ & $\begin{array}{c}0.02 \\
(0.04)\end{array}$ \\
\hline Female & $\begin{array}{l}-0.02 \\
(0.02)\end{array}$ & $\begin{array}{l}-0.02 \\
(0.02)\end{array}$ & $\begin{array}{c}0.00 \\
(0.02)\end{array}$ & $\begin{array}{c}0.01 \\
(0.02)\end{array}$ \\
\hline Single child & $\begin{array}{c}-0.07^{* * *} \\
(0.02)\end{array}$ & $\begin{array}{c}-0.06^{* * *} \\
(0.02)\end{array}$ & $\begin{array}{l}-0.03 \\
(0.02)\end{array}$ & $\begin{array}{l}-0.02 \\
(0.03)\end{array}$ \\
\hline Kindergarten & $\begin{array}{c}0.01 \\
(0.04)\end{array}$ & $\begin{array}{c}0.02 \\
(0.03)\end{array}$ & $\begin{array}{c}0.00 \\
(0.03)\end{array}$ & $\begin{array}{c}0.01 \\
(0.04)\end{array}$ \\
\hline Number of years since parents first migrated & $\begin{array}{c}-0.00^{* * *} \\
(0.00)\end{array}$ & $\begin{array}{l}-0.004^{* *} \\
(0.002)\end{array}$ & $\begin{array}{c}0.00 \\
(0.00)\end{array}$ & $\begin{array}{c}0.00 \\
(0.00)\end{array}$ \\
\hline Family monthly income RMB3000-5000 & $\begin{array}{l}-0.02 \\
(0.02)\end{array}$ & $\begin{array}{l}-0.02 \\
(0.02)\end{array}$ & $\begin{array}{c}0.01 \\
(0.02)\end{array}$ & $\begin{array}{c}0.01 \\
(0.04)\end{array}$ \\
\hline Family monthly income > RMB5000 & $\begin{array}{l}-0.03 \\
(0.03)\end{array}$ & $\begin{array}{l}-0.02 \\
(0.03)\end{array}$ & $\begin{array}{c}0.03 \\
(0.04)\end{array}$ & $\begin{array}{c}0.04 \\
(0.04)\end{array}$ \\
\hline Father has high school education or above & $\begin{array}{c}-0.06^{* * * *} \\
(0.02)\end{array}$ & $\begin{array}{l}-0.06^{* *} \\
(0.03)\end{array}$ & $\begin{array}{c}0.02 \\
(0.03)\end{array}$ & $\begin{array}{c}0.02 \\
(0.03)\end{array}$ \\
\hline Mother has high school education or above & $\begin{array}{c}0.02 \\
(0.03)\end{array}$ & $\begin{array}{c}0.03 \\
(0.03)\end{array}$ & $\begin{array}{l}-0.03 \\
(0.03)\end{array}$ & $\begin{array}{l}-0.04 \\
(0.04)\end{array}$ \\
\hline Province of origin & & & & \\
\hline Jiangsu & $\begin{array}{c}0.05 \\
(0.05)\end{array}$ & $\begin{array}{c}0.06 \\
(0.04)\end{array}$ & $\begin{array}{c}-0.15^{* * *} \\
(0.05)\end{array}$ & $\begin{array}{c}-0.16^{* * *} \\
(0.05)\end{array}$ \\
\hline Anhui & $\begin{array}{c}0.04 \\
(0.03)\end{array}$ & $\begin{array}{c}0.03 \\
(0.03)\end{array}$ & $\begin{array}{c}0.02 \\
(0.03)\end{array}$ & $\begin{array}{c}0.01 \\
(0.03)\end{array}$ \\
\hline Jiangxi & $\begin{array}{l}0.07 * * \\
(0.03)\end{array}$ & $\begin{array}{c}0.07 \\
(0.05)\end{array}$ & $\begin{array}{c}0.00 \\
(0.05)\end{array}$ & $\begin{array}{c}0.00 \\
(0.05)\end{array}$ \\
\hline Henan & $\begin{array}{l}0.05 \\
(0.04)\end{array}$ & $\begin{array}{c}0.04 \\
(0.04)\end{array}$ & $\begin{array}{c}0.04 \\
(0.04)\end{array}$ & $\begin{array}{c}0.03 \\
(0.05)\end{array}$ \\
\hline Sichuan & $\begin{array}{c}0.10^{* * *} \\
(0.04)\end{array}$ & $\begin{array}{l}0.10^{* *} \\
(0.04)\end{array}$ & $\begin{array}{l}0.07 * \\
(0.04)\end{array}$ & $\begin{array}{c}0.06 \\
(0.05)\end{array}$ \\
\hline Student Age in months & YES & YES & YES & YES \\
\hline Father's occupation dummies & YES & YES & YES & YES \\
\hline Observations & 1633 & 1633 & 1633 & 1633 \\
\hline
\end{tabular}

Note: Numbers reported are marginal effects, not regression coefficients. For parental overall satisfaction, reported numbers represent marginal changes in probability from being "satisfied" to "very satisfied". For parental assessment of school quality, reported numbers represent marginal changes in probability from "similar to schools at home" to "better than schools at home". Numbers reported in parentheses are standard errors clustered at the class level. $* * *, * *$, and * stands for statistical significance at the $1 \%, 5 \%$ and $10 \%$ level, respectively. 
Figure 1: Histogram of Standardized Test Scores

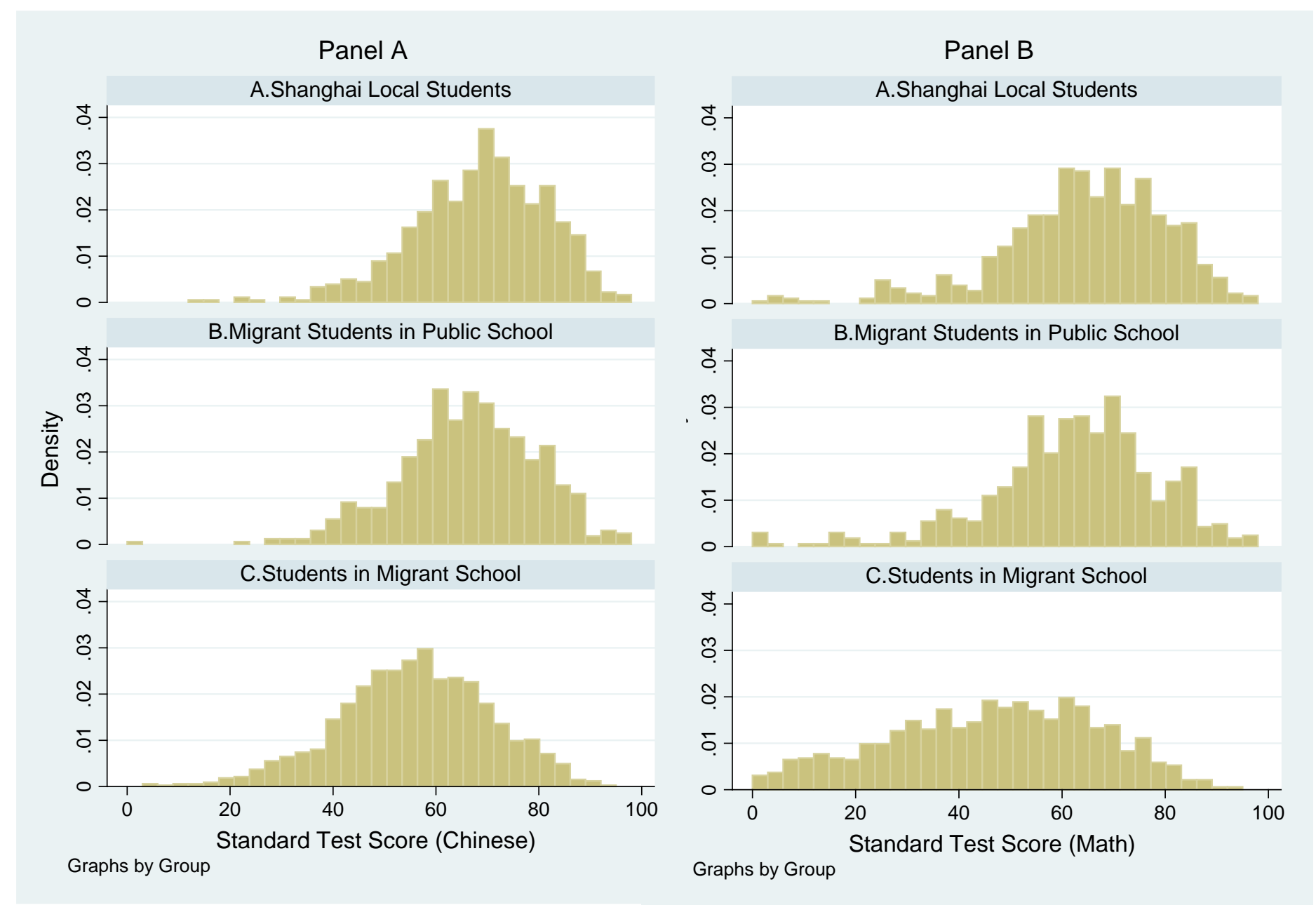

